\title{
Contribution of physical fitness, cerebrovascular reserve and cognitive stimulation to cognitive function in post- menopausal women
}

\author{
Gail A. Eskes ${ }^{1,2 *}$, Stewart Longman ${ }^{3}$,Allison D. Brown ${ }^{2}$, Carly A. McMorris ${ }^{2}$, Kristopher D. Langdon $^{1,4}$, \\ David B. Hogan ${ }^{5,6}$ and Marc Poulin ${ }^{2,6,78,9 *}$
}

1 Department of Psychiatry, Faculty of Medicine, Dalhousie University, Halifax, NS, Canada

2 Department of Physiology and Pharmacology, Faculty of Medicine, University of Calgary, Calgary, AB, Canada

${ }^{3}$ Psychology Service, Foothills Medical Centre, Calgary, AB, Canada

${ }^{4}$ Division of BioMedical Sciences, Faculty of Medicine, Memorial University, St. John's, NL, Canada

${ }^{5}$ Department of Medicine, Faculty of Medicine, University of Calgary, Calgary, AB, Canada

${ }^{6}$ Department of Clinical Neurosciences, Faculty of Medicine, University of Calgary, Calgary, AB, Canada

7 Hotchkiss Brain Institute, Faculty of Medicine, University of Calgary, Calgary, AB, Canada

${ }^{8}$ Faculty of Medicine, Libin Cardiovascular Institute of Alberta, University of Calgary, Calgary, AB, Canada

${ }^{9}$ Faculty of Kinesiology, University of Calgary, Calgary, AB, Canada

\section{Edited by:}

Arthur F. Kramer, University of Illinois at Urbana-Champaign, USA

\section{Reviewed by:}

Michelle W. Voss, University of Illinois at Urbana-Champaign, USA Kirk I. Erickson, Beckman Institute for Advanced Science and Technology, USA

\section{${ }^{*}$ Correspondence:}

Gail A. Eskes, Department of Psychiatry, Dalhousie University, Rm 4080, Abbie J. Lane Bldg, 5909 Veterans Memorial Lane, Halifax, NS B3H 2E2, Canada.

e-mail: gail.eskes@dal.ca;

Marc Poulin, Department of Physiology and Pharmacology, University of Calgary, HMRB-210, 3330 Hospital Drive NW Calgary, AB, T2N 4N1,

Canada.

e-mail:poulin@ucalgary.ca
Studies of the effects of physical fitness on cognition suggest that exercise can improve cognitive abilities in healthy older adults, as well as delay the onset of age-related cognitive decline. The mechanisms for the positive benefit of exercise and how these effects interact with other variables known to influence cognitive function (e.g., involvement in cognitive activities) are less well understood. The current study examined the associations between the physical fitness, cerebrovascular blood flow regulation and involvement in cognitive activities with neuropsychological function in healthy post-menopausal women. Methods: Forty-two healthy women between the ages of 55 and 90 were recruited. Physical fitness $\left(\mathrm{V}_{2}\right.$ max), cerebrovascular reserve (cerebral blood flow during rest and response to an increase in end-tidal (i.e., arterial) $\mathrm{PCO}_{2}$ ), and cognitive activity (self-reported number and hours of involvement in cognitive activities) were assessed. The association of these variables with neuropsychological performance was examined through linear regression. Results: Physical fitness, cerebrovascular reserve and total number of cognitive activities (but not total hours) were independent predictors of cognitive function, particularly measures of overall cognitive performance, attention and executive function. In addition, prediction of neuropsychological performance was better with multiple variables than each alone. Conclusions: Cognitive function in older adults is associated with multiple factors, including physical fitness, cerebrovascular health and cognitive stimulation. Interestingly, cognitive stimulation effects appear related more to the diversity of activities, rather than the duration of activity. Further examination of these relationships is ongoing in a prospective cohort study.

Keywords: aging, cognitive function, fitness, cerebrovascular reserve, cognitive activity

\section{INTRODUCTION}

Declines in certain cognitive domains with aging and an increase in the likelihood of dementia have been shown consistently in a number of large cross-sectional or longitudinal studies (e.g., Salthouse, 1998; Wilson et al., 2002; Seshadri and Wolf, 2007). With societal aging and the concomitant anticipated increase in the number of individuals suffering from a dementia, the need to identify risk as well as protective factors for age-associated cognitive decline has lead to a large body of research and controversy on this topic (Salthouse, 2006; Hertzog et al., 2009). Potential determinants of cognitive status with aging include a variety of genetic and environmental factors, such as apolipoprotein E genotype, obesity, diabetes, hypertension, head trauma, and systemic illnesses (Fotuhi et al., 2009; Oveisgharan and Hachinski, 2010).
In addition to physiological and clinical factors, intellectual stimulation (e.g., education) and psychosocial engagement (e.g., social interactions) may also play a modifying role, potentially through the development of cognitive reserve (the availability of additional neural or cognitive resources that allow increased compensation for aging-related deterioration; Mortimer, 1997; Scarmeas et al., 2001; Bennett et al., 2005). An oft-quoted example of research supporting this proposition is found in the Nun study (Snowdon et al., 1996), in which linguistic abilities early in life predicted the likelihood of developing Alzheimer's disease in later years. A number of studies have also found that higher levels of selfreported involvement in cognitively stimulating activities, either early or later in life, are associated with better cognitive function or a reduced risk of cognitive decline or dementia (Christensen and MacKinnon, 1993; Fabrigoule et al., 1995; Wilson et al., 1999, 2003b; 
Friedland et al., 2001; Scarmeas et al., 2001; Verghese et al., 2003), although not all studies find an association (Aartsen et al., 2002) and the causal direction has been questioned (Hultsch et al., 1999). While care has been taken in many longitudinal studies to try and tease apart the causal direction of the association, it remains impossible to determine whether cognitive activity delays or prevents the onset of dementia per se, or if those who are more prone to develop dementia spontaneously engage in fewer cognitive activities. The ability of cognitive training to improve cognitive function in older adults and/or in those with pre-existing cognitive dysfunction has been shown in some intervention trials (Ball et al., 2002; Belleville, 2008), suggesting that stimulation from a cognitively active lifestyle could play a causal role.

Given the potential role of risk factors for vascular disease in the expression of cognitive decline, physical activity has attracted attention as a potential protective agent. Physical activity improves cardiovascular health and decreases the occurrence of obesity, diabetes mellitus, and other diseases (RodriguezColon et al., 2009). Being overweight, even after controlling for obesity-related diseases and type II diabetes, is associated with greater age-related cognitive decline (Cukierman et al., 2005; Nilsson and Nilsson, 2009). The effects of cardiovascular activity on brain health have been a recent focus of attention in both animal and human studies (Cotman et al., 2007; Kramer and Erickson, 2007). Experimental animal studies have shown that aerobic exercise results in increases in neuroplasticity-associated proteins (e.g., BDNF and FGF2) (Gomez-Pinilla et al., 2002; Ding et al., 2006) and angiogenesis (Swain et al., 2003) and improves learning and memory (van Praag et al., 1999). In humans both retrospective and prospective studies have linked physical exercise to an attenuation of cognitive decline with aging (Friedland et al., 2001; Laurin et al., 2001; Andel et al., 2008). Other potential mechanisms for the protective effects of exercise include increases in cerebrovascular conductance, decreases in blood pressure, increases in serum antioxidant protein markers, decreases in oxidative stress, and changes in plasma viscosity (Pialoux et al., 2009; Brown et al., 2008).

The interaction between physical activity and cognitive activity in terms of potential effects on cognition has not been looked at in detail. One retrospective study examined this phenomenon and found that an increase in the diversity of physical and intellectual activities was associated with a lower incidence of dementia (Friedland et al., 2001). In this study, however, there was no detailed description of benefits for specific cognitive domains (e.g. attention, speed, or executive function). Bielak et al. (2007) examined reported physical and cognitive activity in the Victoria Longitudinal Study and found that both types of activity were significant predictors of information processing efficiency in older adults. The joint contribution of cognitive and physical activity to fluid intelligence in older subjects was also reported in a cross-sectional study (Christensen and MacKinnon, 1993).

We sought to further investigate the interaction between effects of physical activity and cognitive activity on cognitive function and a potential mediating factor, cerebrovascular reserve. In the current study of healthy older post-menopausal women, we assessed the impact of the amount and diversity of self-reported cognitive activities on cerebrovascular conductance, $\dot{\mathrm{VO}}_{2} \max$, and cognition using a detailed neuropsychological battery. Our main question of interest was whether cognitive activity predicted cognitive function when the effects of physical fitness and/or cerebrovascular reserve were taken into account, i.e., does cognitive activity have independent effects on cognitive function? In addition, we were interested in examining whether prediction of cognitive function was enhanced when multiple variables were taken into account.

\section{MATERIALS AND METHODS SUBJECTS}

The methods used in this cross-sectional study have been described before (Brown et al., 2008). For the purposes of these analyses, the final sample of subjects included 42 post-menopausal women recruited from the community (mean age $=65.1$ years; standard deviation, $\mathrm{SD}=8.4$; range $=50-90$ years), mean education $=15.2$ years $(S D=2.0$; range $=11-19$; see Table 1$)$. Eligibility criteria included being non-smoking, able to perform moderate exercise (determined by the study physician), not morbidly obese (BMI $<37 \mathrm{~kg} / \mathrm{m}^{2}$ ), and free of significant respiratory/ cerebrovascular disease (including normal spirometry and no significant carotid artery stenosis on carotid Doppler studies) or any other major co-morbidities (e.g., recent surgery, major trauma in last 6 months, asthma, sleep apnea, stroke, chronic migraine, blood clots/thrombosis). Subjects were also excluded if taking select prescription medicine such as hormone replacement therapy, beta-blockers, anti-depressants, blood thinners, tamoxifen, raloxifene, corticosteroids, adrenaline/epinephrine or anti-arrhythmics.

The study was approved by the Conjoint Health Research Ethics Board, University of Calgary. Informed consent was obtained from all subjects.

\section{TESTING}

There were four testing sessions, described in detail previously (Brown et al., 2008). These sessions consisted of a screening visit, a graded exercise test, vascular flow testing, and neuropsychological testing. Briefly, the screening visit included collection of demographic and anthropometric measures, completion of physical and cognitive activity questionnaires (see below), spirometry testing, and a carotid artery ultrasound.

Table 1 | Characteristics of subjects.

\begin{tabular}{|c|c|c|c|}
\hline & $N$ & Mean & SD \\
\hline Age (years) & 42 & 65.1 & 8.4 \\
\hline Education (years) & 42 & 15.2 & 2.0 \\
\hline$\dot{\mathrm{VO}}_{2}$ max, relative $\left(\mathrm{ml} \mathrm{kg}^{-1} \mathrm{~min}^{-1}\right)$ & 40 & 25.6 & 5.6 \\
\hline$\dot{\mathrm{VO}}_{2}$ max, absolute $\left(I \mathrm{~min}^{-1}\right)$ & 40 & 1.67 & 0.31 \\
\hline$\dot{\mathrm{VO}}_{2}$ max, $\%$ predicted & 40 & 101.2 & 22.6 \\
\hline $\mathrm{MAP}_{\mathrm{REST}}(\mathrm{mmHg})$ & 42 & 74.2 & 13.2 \\
\hline $\mathrm{CVC}_{\text {REST }}\left(\mathrm{cm} \mathrm{s}^{-1} \mathrm{mmHg}^{-1}\right)$ & 34 & 0.95 & 0.20 \\
\hline $\mathrm{MAP}_{\mathrm{ISO}}(\mathrm{mmHg})$ & 41 & 79.3 & 9.9 \\
\hline $\mathrm{CVC}_{\text {ISO }}\left(\mathrm{cm} \mathrm{s}^{-1} \mathrm{mmHg}^{-1}\right)$ & 34 & 0.77 & 0.15 \\
\hline $\begin{array}{l}\text { Number of different cognitive } \\
\text { activities (per year) }\end{array}$ & 42 & 4.4 & 1.9 \\
\hline Number of cognitive activity & 42 & 18.0 & 11.1 \\
\hline
\end{tabular}


On the second visit, a graded exercise test was conducted on a modified recumbent cycle ergometer and maximal oxygen consumption ( $\mathrm{VO}_{2}$ max) was calculated for each individual as a measure of fitness. Percent of predicted values for $\dot{\mathrm{VO}}_{2}$ max were used as a measure of fitness in the analyses.

The procedures in the third visit included blood sampling for hormone levels (used to verify post-menopausal status and absence of hormone replacement therapy), and measurements of right middle cerebral artery flow velocity via transcranial Doppler ultrasound during resting conditions, as well as during euoxic hypercapnia (4-5 min each at 1.0, 5, 8 Torr, above resting end-tidal $\mathrm{PCO}_{2}$ values while holding end-tidal $\mathrm{PO}_{2}$ levels constant at resting values) and then returning to end-tidal $\mathrm{PCO}_{2}$ values to 1 Torr above resting levels), and sub-maximal exercise (two 6-min periods of peddling at $40 \%$ of $\dot{\mathrm{VO}} 2$ max output separated by a 6 -min rest period). Measurements of cerebral blood flow indices were made via transcranial Doppler ultrasound and variables of interest included resting velocity associated with the maximum frequency of the Doppler shift (averaged over each heart beat; $\overline{\mathrm{V}} \mathrm{P}$ ), and two indices of cerebrovascular health (MAP, mean arterial blood pressure, and CVC, cerebrovascular conductance or tone, calculated as $\overline{\mathrm{V}} \mathrm{P} / \mathrm{MAP}$ ). Indices of cerebrovascular health used for the current analyses included resting MAP and CVC $\left(\mathrm{MAP}_{\mathrm{REST}}, \mathrm{CVC}_{\mathrm{REST}}\right)$, and isocapnic MAP and CVC, when end-tidal values were held constant at near-resting levels ( $\mathrm{MAP}_{\mathrm{ISO}}$ and $\left.\mathrm{CVC}_{\mathrm{ISO}}\right)$. Some subjects were not able to complete all tests and the number for each analysis is noted in Table $\mathbf{1 .}$

The fourth visit took place 1-3 weeks after Visit 3 and involved a neuropsychological assessment with a test battery listed in Table 2 . Individual subtest raw scores were converted to $Z$-scores, based on the mean and SD of the entire group $(\mathrm{n}=42$; Table 2$)$ and summed to provide relative domain scores for each subject. To represent overall cognitive ability, a global cognitive score was derived from the summation of domain Z-scores.

\section{COGNITIVE ACTIVITY OUESTIONNAIRE}

Subjects were asked to estimate the frequency and amount of time they spent in a list of 12 activity categories judged to be associated mainly with cognitive integration and/or activity. These activity

\section{Table 2 | Neuropsychological performance of overall group.}

\begin{tabular}{llc}
\hline Cognitive domain & Neuropsychological tests & Mean (SD) \\
\hline Verbal ability & WASI Vocabulary & $51.9(10.9)$ \\
& D-KEFS Verbal Fluency (C score) & $12.6(3.3)$ \\
Perception & WASI Matrix Reasoning & $60.8(11.9)$ \\
& Benton Judgment of Line Orientation & $24.8(5.3)$ \\
Processing & Digit Symbol Modality Test & $46.6(7.6)$ \\
Speed & D-KEFS Color-Word Interference & $11.3(2.1)$ \\
& Test (conditions 1, 2) & $11.5(2.1)$ \\
Attention & Auditory Consonant Trigrams Test & $45.3(6.3)$ \\
Verbal memory & Buschke Selective Reminding Test & $48.9(9.1)$ \\
Visual memory & Medical College of Georgia Complex & $27.0(7.4)$ \\
& Figures Test & $26.7(7.6)$ \\
Executive function & D-KEFS Card Sorting Test & $12.4(2.3)$ \\
& Color-Word Interference & $11.5(2.5)$ \\
& Test (conditions 3,4) & $11.9(1.7)$ \\
& Verbal Fluency (LF score) & $13.2(4.2)$
\end{tabular}

categories included: board games/chess/checkers; playing bridge; crosswords/word search/sudoku; reading/book club; playing a musical instrument; using the computer/internet; drawing/painting/photography; trivia; arts/crafts/scrapbooking; knitting/sewing/ quilting; puzzles (See Appendix for questionnaire). They rated how many times per week and/or per month throughout the past year they engaged in these activities and estimated the number of minutes spent in each session. Subjects were also allowed to indicate other activities not on the list. This open-ended category was used by 14 respondents and subjects reported activities such as attending or teaching classes, writing, volunteer work, baking, singing, video shooting/editing, social activity, and bird watching. We used an approach similar to Friedland et al., (2001) and calculated two measures for each subject: (1) the total number of different categories of activities a subject engaged in throughout the past year ("Diversity"); and (2) the total time spent in cognitive activities summed over all activities for the last year ("Duration").

\section{ANALYSES}

Descriptive statistics (mean and standard deviation) were derived for age, education, fitness ( $\left.\mathrm{V}_{2} \max \right)$, and vascular health (MAP, CVC) for the entire group (see Table 1). Correlations were computed to examine the relationships between our two measures of cognitive activity and select demographic characteristics (age, education) and measures of fitness and vascular health, and cognition. Since the predictive value of cerebrovascular reserve and fitness in relation to cognitive function was previously reported by Brown et al. (2008), we conducted a series of hierarchical linear regressions to examine the additional value of including cognitive activities in predicting cognitive function. The predictive relationship between demographics, vascular health and cognitive activities with cognitive domain scores was examined by a series of hierarchical linear regressions using SPSS 17 with age (years) and education (years) introduced in Step 1 of the equation, followed by fitness $\left(\mathrm{VO}_{2} \max\right.$, $\%$ predicted) or each cerebrovascular reserve variable (MAP or CVC) in Step 2 and cognitive activities (both number of activities and duration) in Step 3.

\section{RESULTS}

\section{CORRELATIONS}

Table 3 presents Pearson correlations between our two measures of cognitive activity and select variables of interest. Number of cognitive activities (but not duration) was significantly related to a variety of measures of cognitive ability, including global cognition, speed of processing, attention, verbal and visual memory, verbal ability and executive function. Cognitive activity was not directly related to fitness (predicted $\dot{\mathrm{VO}}_{2} \max$ ) or vascular health variables.

\section{PREDICTION OF COGNITIVE DOMAIN SCORES}

The final models of the 3-step hierarchical regressions for predicting global cognitive performance are presented in Tables 4-6. These results show that the diversity of cognitive activities (but not the overall duration spent in these activities) added significantly to the prediction of global cognitive performance, after demographic variables and measures of fitness and vascular health were first taken into account. Table 4 demonstrates that, with age and education entered as a first step, the model accounted for $22 \%$ of the variance. When fitness $\left(\dot{\mathrm{VO}}_{2} \max \right)$ was entered in the second step, an 
Table 3 | Correlation of cognitive activity with demographic variables, fitness, vascular health and relative cognitive domain scores.

\begin{tabular}{lll}
\hline Variables & $\begin{array}{l}\text { Cognitive activity } \\
\text { (number) }\end{array}$ & $\begin{array}{l}\text { Cognitive activity } \\
\text { (duration) }\end{array}$ \\
\hline Age & 0.19 & 0.21 \\
Education & 0.21 & 0.20 \\
VO $_{2}$ max (\% predicted) & 0.27 & 0.16 \\
$\mathrm{MAP}_{\text {REST }}$ & -0.03 & 0.15 \\
$\mathrm{MAP}_{\text {ISO }}$ & -0.30 & 0.08 \\
$\mathrm{CVC}_{\mathrm{REST}}$ & 0.17 & 0.07 \\
$\mathrm{CVC}_{\text {ISO }}$ & 0.18 & -0.17 \\
Global score $_{\text {Verbal ability }}$ & $0.49^{* * *}$ & -0.01 \\
Perception $_{\text {Processing speed }}$ & $0.36^{*}$ & -0.12 \\
Attention & 0.30 & -0.05 \\
Verbal memory & $0.46^{* *}$ & 0 \\
Visual memory & $0.36^{*}$ & 0.14 \\
Executive function & $0.35^{*}$ & -0.02 \\
& $0.39^{*}$ & -0.06 \\
\hline
\end{tabular}

${ }^{*} p<0.05 ;{ }^{*} p<0.01 ;{ }^{* *} p<0.001$.

Table 4 | Summary of final significant model for prediction of global cognitive score when $\mathrm{VO}_{2}$ max is included.

\begin{tabular}{lc}
\hline Predictors & Beta \\
\hline Age (years) & $-0.549^{* * *}$ \\
Education (years) & 0.158 \\
$\dot{\mathrm{V}} \mathrm{O}_{2}$ max & 0.252 \\
Cognitive activities (number) & $0.5^{* * *}$ \\
Cognitive activities (hrs) & -0.044
\end{tabular}

Models 1 and 2 are not shown. $R^{2}=0.22$ for Step $1(p<0.01), \Delta R^{2}=0.12$ for Step $2(p<0.05)$ and 0.21 for Step $3(p<0.01)$. See text for predictors at each step. $\dot{V}_{2}$ max $=$ maximal oxygen consumption (\% predicted). ${ }^{*} p<0.05,{ }^{* *} p<0.01,{ }^{* *} p<0.001$.

Table 5 | Summary of final significant model for prediction of global cognitive score when MAP variables are included.

\begin{tabular}{lclc}
\hline Predictors & Beta & Predictors & Beta \\
\hline Age (years) & $-0.436^{* *}$ & Age (years) & $-0.449^{* * *}$ \\
Education (years) & 0.111 & Education (years) & 0.141 \\
MAP $_{\text {REST }}$ & -0.091 & MAP $_{\text {ISO }}$ & -0.138 \\
Cognitive activities & $0.548^{* * *}$ & Cognitive & $0.468^{* * *}$ \\
(number) & & activities (number) & \\
Cognitive activities & -0.023 & Cognitive & -0.018 \\
(hrs) & & activities (hrs)
\end{tabular}

Models 1 and 2 are not shown. For models including $M_{A P} P_{\text {REST }}(n=42), R^{2}=0.21$ for Step 1(p<0.01), $\Delta R^{2}=0.02$ for Step 2 and 0.27 for Step $3(p<0.001)$. For models including MAP ${ }_{\text {ISO }}(n=41), R^{2}=0.25$ for Step $1(p<0.01), \Delta R^{2}=0.08(p<0.05)$ for Step 2 and 0.18 for Step $3(p<0.01)$. See text for predictors at each step.

$M A P_{\text {REST }}=$ resting Mean Arterial Blood Pressure; $M A P_{\text {ISO }}=$ isocapnic Mean Arterial Blood Pressure.

Beta $=$ standardized coefficient.

${ }^{*} p<0.05,{ }^{* *} p<0.01,{ }^{*}{ }^{*} p<0.001$.
Table 6 | Summary of final significant model for prediction of global cognitive function when CVC variables are included.

\begin{tabular}{llll}
\hline Predictors & Beta & Predictors & Beta \\
\hline Age (years) & $-0.481^{* *}$ & Age (years) & $-0.431^{* *}$ \\
Education (years) & 0.22 & Education (years) & 0.233 \\
CVC $_{\text {REST }}$ & 0.092 & CVC $_{\text {ISO }}$ & 0.204 \\
Cognitive activities & $0.514^{* * *}$ & Cognitive activities & $0.461^{* *}$ \\
(number) & & (number) & \\
Cognitive activities & -0.04 & Cognitive activities & -0.024 \\
(hrs) & & (hrs) & \\
\hline
\end{tabular}

Models 1 and 2 are not shown. For models including $C V C_{\text {REST }}(n=34), R^{2}=0.25$ for Step $1(p<0.05), \Delta R^{2}=0.03$ for Step 2 and 0.23 for Step $3(p<0.01)$. For models including $C V C_{\text {ISO }}(n=34), R^{2}=0.26$ for Step $1(p<0.01), \Delta R^{2}=0.10$ for Step 2 and 0.18 for Step $3(p<0.05)$. See text for predictors at each step.

$C V C_{R E S T}=$ resting cerebrovascular conductance; $C V C_{I S O}=$ isocapnic cerebrovascular conductance.

Beta $=$ standardized coefficient

${ }^{*} p<0.05,{ }^{* *} p<0.01,{ }^{* * *} p<0.001$

additional $12 \%$ of the variance was explained, with higher fitness associated with better cognitive performance (as reported by Brown et al. 2008). The number and duration of cognitive activities was entered in the third step and accounted for an additional $21 \%$ of the variance, with the final model having an $R^{2}=55 \%(F(5,34)=8.15$, $p<0.001)$. In the final model age and the number of cognitive activities were the only significant predictors, with age inversely and cognitive activities directly associated with better cognitive performance. A similar pattern was seen in terms of the addition of cognitive activities in the third step for all models containing $\mathrm{MAP}_{\mathrm{REST}}, \mathrm{MAP}_{\mathrm{ISO}}, \mathrm{CVC}_{\mathrm{REST}}$, or $\mathrm{CVC}_{\mathrm{ISO}}$ in the second step, i.e., age and number of cognitive activities were significant negative and positive predictors of global cognitive performance in the third step, respectively (Tables $\mathbf{5}$ and $\mathbf{6}$ ). In addition, this same pattern was consistently seen for prediction of other cognitive domains as well, particularly speed of processing, verbal ability, and executive function (Table A1 in Appendix).

\section{DISCUSSION}

The first purpose of this study was to determine whether cognitive activity predicted cognitive function when the effects of physical fitness and/or cerebrovascular reserve were taken into account. Previous analyses with the current population under study identified the importance of fitness and vascular health to cognitive function. In the current report, we extend these findings to show that the diversity (but not the duration) of current engagement in cognitive activity was also an important and statistically significant predictor of cognitive function (after controlling for age), particularly in the domains of global function, processing speed, verbal ability, and executive function.

These findings are in agreement with previous studies in healthy aging populations showing that the level of cognitive activity in which an individual engages in daily life is related to cognitive abilities as well as the risk of dementia (Christensen and MacKinnon, 1993; Hultsch et al., 1999; Wilson et al., 1999, 2002, 2003b; Wang et al., 2002; Verghese et al., 2003). Our data suggest a difference between diversity and duration of cognitive 
stimulation in predictive value, however. Diversity of activities was predictive of cognitive function while overall duration of engagement in these activities was not. A variety of measures of cognitive activity have been used in prior studies, with most using measures that focus on frequency of activity or a composite measure of frequency and diversity. For example, a frequently used activity scale developed by Wilson et al. (2003a) calculates mean activity frequency for 5-6 cognitive activities in adulthood. A composite approach was adopted by Bielak et al. (2007) in the Activity Lifestyle Questionnaire that sums the frequency of engagement ratings in a list of activities. Similar approaches were used by Hultsch et al. in the Victoria Longitudinal Study (Hultsch et al., 1999) and Verghese et al. in the Bronx Aging Study (Verghese et al., 2003). In contrast, Friedland et al. (2001) examined diversity (percent of total number of activities), intensity (sum of total hours per month of activity), and percentage intensity (percent of total activity hours/month in an activity category) in a case control study and found that both diversity and intensity in early and middle adulthood were significantly different in a group with Alzheimer's disease compared to a non-demented control group. In addition, if the population was divided into two groups based on the overall mean level of number of activities, the odds ratio for Alzheimer's disease status was 3.85 in those having less than the mean value. Our data are consistent with the findings regarding the importance of diversity of cognitive engagement as a factor in cognitive function in a healthy, normotensive population. Diversity of stimulation also appears relevant in terms of enhancing the effects of cognitive training in older adults in past research. For example, multi-dimensional cognitive training interventions (e.g., Basak et al., 2008; Carlson et al., 2009) may be more successful in generalizing benefits to untrained tasks compared to more targeted training (Ball et al., 2002). More investigation of the independent influence of diversity compared to frequency/ intensity is needed, particularly in terms of public health recommendations that could be derived from these and related findings by others for both healthy adults and those with a range of risk factors.

The mechanisms underlying the higher scores for global cognition and other cognitive domains in the cognitively active group compared to the inactive group are difficult to elucidate. The mechanisms are likely complex and multi-factorial, and likely involve molecular and neural processes. It is reasonable to speculate that both cognitive and physical activities share similar, or perhaps overlapping, molecular mechanisms that may provide benefits to brain health since both cardiovascular health (Brown et al., 2008) and the number of cognitive activities independently predicted cognitive function. In rat studies, voluntary wheel running increases levels of growth factors (Neeper et al., 1995; GomezPinilla et al., 2002) and combining physical activity with learning and memory paradigms (e.g., Morris water maze) is associated with a further increase in the levels of growth factors that are not accounted for by either alone (Gomez-Pinilla et al., 1998). This additive benefit in neural growth factors is important because growth factors such as brain-derived neurotrophic factor (BDNF) have been implicated in the recovery of cognitive function after brain injury (Griesbach et al., 2009) and could also apply to neural responses associated with aging-induced degeneration. Conversely, antagonizing BDNF's actions impedes recovery of function following experimental ischemia (Ploughman et al., 2009). An increase in proteins associated with enhanced neuroplasticity (i.e., BDNF or FGF2) may help in the delay of cognitive decline due to normal aging processes as well as enhancing cognitive recovery after trauma. In addition, previous research has shown that physical exercise increases levels of serum antioxidant proteins and a reduction in oxidative stress (Pialoux et al., 2009). These changes may lead to improvements in cognitive function, or at least they may help delay the cognitive declines associated with advancing age. The extent that cognitive activity also is associated with these mechanisms in humans deserves investigation.

While these findings are consistent with previous human or animal research on the effects of physical and cognitive activity on cognitive function, there are limitations to this study that lead to the need for caution in interpretation of our results. The sample size is small in this study compared to other studies due to the intensive instrumentation and testing carried out. We only examined healthy, highly educated post-menopausal women who volunteered for this study because we were primarily interested in the relationship between fitness and cognition after menopause. We expect that the findings are applicable to both men and women, but the generalizability of these findings to a larger and more diverse population of men and women should be examined. In addition, the estimates of cognitive activity were derived at the same time as estimates of cognitive function and thus it is not possible to determine cause-effect from these data. It may be that individuals with reduced cognitive abilities spontaneously reduce their involvement in cognitive activities. While current associations do not allow causal interpretations, other longitudinal studies of cognitive activity by other investigators do provide temporal evidence for causal links, however.

In summary, these findings reinforce the idea that cognitive function with aging is multiply determined through a number of factors, including both physical and cognitive activity and thus can be moderated by lifestyle choices. A number of remaining questions need further investigation, however, such as the impact of diversity of activity compared to intensity, and how these effects interact in underlying brain and vascular physiology.

\section{ACKNOWLEDGMENTS}

This study was supported by an Establishment Grant from the Alberta Heritage Foundation for Medical Research (AHFMR; Dr. Poulin); by a Canadian Institutes of Health Research Operating Grant (CIHR; to Drs Eskes, Hogan, Longman and Poulin), and by a New Opportunities Funding Award from the Canadian Foundation for Innovation (Dr. Poulin). Dr. Eskes was supported by an AHFMR Visiting Scientist Award and a Heart and Stroke Foundation Visiting Scholar Award; Dr. Longman was supported by the Calgary Health Region; Ms. Brown was supported by studentships from the Natural Sciences and Engineering Research Council of Canada and the AHFMR. Dr. Langdon was supported by a fellowship from CIHR (to Dr. Eskes). Dr. Hogan receives support from the Brenda Strafford Foundation Chair in Geriatric Medicine, University of Calgary. Dr. Poulin was supported by an AHFMR Senior Medical Scholar Award and the Strafford Foundation. We thank Rylee Stephens for her invaluable help with data analyses. 


\section{REFERENCES}

Aartsen, M. J., Smits, C. H. M., vanTilburg, T., Knipscheer, K. C. P. M., and Deeg, D. J.H. (2002). Activity in older adults: cause or consequence of cognitive functioning? A longitudinal study on everyday activities and cognitive performance in older adults. J. Gerontol. 57B, P153-P162.

Andel, R., Crowe, M., Pedersen, N. L., Fratiglioni, L., Johansson, B., and Gatz, M. (2008). Physical exercise at midlife and risk of dementia three decades later: a population-based study of Swedish twins. J. Gerontol. 63A, 62-66.

Ball, K., Berch, D. B., Helmers, K. F., Jobe, J. B., Leveck, M. D., Marsiske, M. Morris, J. N., Rebok, G. W., Smith D. M., Tennstedt, S. L., Unverzagt, F. W., and Willis, S. L. (2002). Effects of cognitive training interventions with older adults. JAMA 288, 2271-2281.

Basak, C., Boot, W. R., Voss, M. W., and Kramer,A. F. (2008). Can training in a real-time strategy video game attenuate cognitive decline in older adults? Psychol. Aging 23, 765-777.

Belleville, S. (2008). Cognitive training for persons with mild cognitive impairment. Int. Psychogeriatr. 20, 57-66.

Bennett, D. A., Schneider, J. A., Wilson, R. S., Bienias, J.L., and Arnold, S.E. (2005). Education modifies the association of amyloid but not tangles with cognitive function. Neurology 65, 953-955

Bielak, A. A. M., Hughes, T. F., Small, B. J., and Dixon, R. A. (2007). It's never too late to engage in lifestyle activities: Significant concurrent but not change relationships between lifestyle activities and cognitive speed. $J$. Gerontol. 62B, P331-P339.

Brown, A. D., McMorris, C. A., Longman, R.S., Leigh, R., Hill, M.D., Friedenreich, C. M., and Poulin, M. J. (2008). Effects of cardiorespiratory fitness and cerebral blood flow on cognitive outcomes in older women. Neurobiol. Aging. doi: 10.1016/j.neurobiolaging.2008.11.002.

Carlson, M. C., Erickson, K. I., Kramer, A. F., Voss, M. W., Bolea, N., Mielke, M. McGill, S., Rebok, G. W., Seeman, T., and Fried, L. P. (2009). Evidence for neurocognitive plasticity in at-risk older adults: The Experience Corps program. J. Gerontol. A Biol. Sci. Med. Sci. 64, 1275-1282.

Christensen, H., and MacKinnon, A. (1993). The association between mental, social and physical activity and cognitive performance in young and old subjects. Age Ageing 22, 175-182.

Cotman, C. W., Berchtold, N. C., and Christie, L.-A. (2007). Exercise builds brain health: key roles of growth factor cascades and inflammation. Trends Neurosci. 30, 464-472.

Cukierman, T., Gerstein, H. C., and Williamson,J.D. (2005).Cognitive decline and dementia in diabetes - systematic overview of prospective observational studies. Diabetologia 48, 2460-2469.

Ding, Q., Vaynman, S., Akhavan, M. Ying, Z., and Gomez-Pinilla, F. (2006). Insulin-like growth factor 1 interfaces with brain-derived neurotrophicfactormediated synaptic plasticity to modulate aspects of exercise-induced cognitve function. Neuroscience 140, 823-833.

Fabrigoule, C., Letenneur, L., Dartigues, J. F., Zarrouk, M., Commenges, D., and Barberger-Gateau,P. (1995). Social and leisure activities and risk of dementia: A prospective longitudinal study. $J$. Am. Geriatr. Soc. 43, 485-490.

Fotuhi, M.,Hachinski, V., and Whitehouse, P. J. (2009). Changing perspectives regarding late-life dementia. Nat. Rev. Neurol. 5, 649-658.

Friedland, R. P., Fritsch, T., Smyth, K. A., Koss, E., Lerner, A. J., Chen, C. H., Petot, G. J., and Debanne, S. M. (2001). Patients with Alzheimer's disease have reduced activities in midlife compared with healthy control-group members. Proc. Natl. Acad. Sci. U.S.A. $98,3440-3445$.

Gomez-Pinilla, F., So, V., and Kesslak, J. P. (1998). Spatial learning and physical activity contribute to the induction of fibroblast growth factor: neural substrates for increased cognition associated with exercise. Neuroscience 85, 53-61.

Gomez-Pinilla, F., Ying, Z., Roy, R. R. Molteni, R., and Edgerton, V. R. (2002). Voluntary exercise induces a BDNF-mediated mechanism that promotes neuroplasticity. J. Neurophysiol. $88,2187-2195$.

Griesbach, G. S., Hovda, D. A., and Gomez-Pinilla, F. (2009). Exerciseinduced improvement in cognitive performance after traumatic brain injury in rats is dependent on BDNF activation. Brain Res. 1288, 105-115.

Hertzog, C., Kramer,A.F., Wilson, R.S., and Lindenberger, U. (2009). Enrichment effects on adult cognitive development. Can the functional capacity of older adults be preserved and enhanced? Psychol. Sci. Public Int. 9, 1-65.

Hultsch, D. F., Hertzog, C., Small, B. J., and Dixon, R. A. (1999). Use it or lose it: engaged lifestyle as a buffer of cognitive decline in aging? Psychol. Aging $14,245-263$

Kramer, A. F., and Erickson, K. I. (2007) Capitalizing on cortical plasticity: influence of physical activity on cognition and brain function. Trends Cogn. Sci. 11, 342-348.

Laurin, D., Verreault, R., Lindsay, J., MacPherson, K., and Rockwood, K. (2001). Physical activity and risk of cognitive impairment and dementia in elderly persons. Arch. Neurol. 58, 498-504.

Mortimer, J. A. (1997). Brain reserve and the clinical expression of Alzheimer's disease. Geriatrics 52(Suppl. 2), S50-S53.

Neeper, S. A., Gomez-Pinilla, F., Choi, J., and Cotman, C. (1995). Exercise and brain neurotrophins. Nature 373, 109.

Nilsson, L. G., and Nilsson, E. (2009). Overweight and cognition. Scand. J. Psychol. 50, 660-667.

Oveisgharan, S., and Hachinski, V. (2010) Hypertension, executive dysfunction and progression to dementia: The Canadian Study of Health and Aging. Arch. Neurol. 67, 187-192.

Pialoux, V., Brown, A. D., Leigh, R. Friedenreich, C. M., and Poulin, M. J. (2009). Effect of cardiorespiratory fitness on vascular regulation and oxidative stress in postmenopausal women. Hypertension 54, 1014-1020.

Ploughman, M., Windle, V., MacLellan, C L., White, N., Dore, J. J., and Corbett, D. (2009). Brain-derived neurotrophic factor contributes to recovery of skilled reaching after focal ischemia in rats. Stroke 40, 1490-1495.

Rodriguez-Colon, S. M., Mo, J., Duan, Y., Liu, J., Caulfield, J. E., Jin, X., and Liao, D. (2009). Metabolic syndrome clusters and the risk of incident stroke: the atherosclerosis risk in communities (ARIC) study. Stroke 40, 200-205.

Salthouse, T. A. (1998). Independence of age-related influences on cognitive abilities across the life-span. Dev Psychol. 34, 851-864.

Salthouse, T. A. (2006). Mental exercise and mental aging. Perspect. Psychol. Sci. 1, 68-87.

Scarmeas, N., Levy, G., Tang, M.-X., Manly, J., and Stern, Y. (2001). Influence of leisure activity on the incidence of Alzheimer's disease. Neurology 57, 2236-2242.

Seshadri, S., and Wolf, P. A. (2007). Lifetime risk of stroke and dementia: current concepts, and estimates from the Framingham Study. Lancet Neurol. 6, 1106-1114

Snowdon, D. A., Kemper, S. J., Mortimer, J. A., Greiner, L. H., Wekstein, D. R., and Markesbery, W. R. (1996). Linguistic ability in early life and cognitive function and Alzheimer's disease in late life. Findings from the Nun Study. JAMA $275,528-532$

Swain, R. A., Harris, A. B., Wiener, E. C., Dutka, M.V., Morris, H. D., Thelen, B. E., Konda, S., Engberg, K., Lauterbur, P. C., and Greenough, W. T. (2003). Prolonged exercise induces angiogenesis and increases cerebral blood volume in primary motor cortex of the rat. Neuroscience 117, 1037-1046.

van Praag, H., Christie, B. R., Sejnowski, T. J., and Gage, F. H. (1999). Running enhances neurogenesis, learning, and long-term potentiation in mice. Proc. Natl. Acad. Sci. U.S.A. 96 13427-13431.
Verghese, J., Lipton, R. B., Katz, M. J., Hall, C. B., Derby, C. A., Kuslansky, G., Ambrose, A. F., Sliwinski, M., and Buschke, H. (2003). Leisure activities and the risk of dementia in the elderly. N. Engl. J. Med. 348, 2508-2516.

Wang, H. -X., Karp, A., Winblad, B., and Fratiglioni, L. (2002). Late-life engagement in social and leisure activities is associated with a decreased risk of dementia: a longitudinal study from the Kungsholmen project. Am. J. Epidemiol. 155, 1081-1087.

Wilson, R. S., Barnes, L. L., and Bennett, D. A. (2003a). Assessment of lifetime participation in cognitively stimulating activities. J. Clin. Exp. Neuropsychol. 25, 634-642.

Wilson, R. S., Beckett, L. A., Barnes, L. L. Schneider, J. A., Bach, J., Evans, D. A., and Bennett, D. A. (2002). Individual differences in rates of change in cognitive abilities of older persons. Psychol. Aging 17, 179-193.

Wilson, R. S., Bennett, D. A., Beckett, L. A., Morris, M. C., Gilley, D. W., Bienias, J. L., Scherr, P. A., and Evans, D. A. (1999). Cognitive activity in older persons from a geographically defined population. J. Gerontol. Psychol. Sci. 54B, P155-P160.

Wilson, R. S., Bennett, D. A., Bienias, J. L., Mendes de Leon, C., Morris, M.C., and Evans, D. A. (2003b). Cognitive activity and cognitive decline in a biracial community population. Neurology 61 , 812-816.

Wilson, R.S., Mendes de Leon, C. F., Barnes, L. L., Schneider, J. A., Bienias, J. L., Evans, D. A., and Bennett, D. A. (2002) Participation in cognitively stimulating activities and risk of incident Alzheimer disease. JAMA 287, 742-748.

Conflict of Interest Statement: The authors declare that the research was conducted in the absence of any commercial or financial relationships that could be construed as a potential conflict of interest.

Received: 31 May 2010; paper pending published: 13 June 2010; accepted: 03 August 2010; published online: 13 October 2010.

Citation: Eskes GA, Longman S, Brown $A D$, McMorris CA, Langdon KD, Hogan DB and Poulin M (2010). Contribution of physical fitness, cerebrovascular reserve and cognitive stimulation to cognitive function in postmenopausal women. Front. Ag. Neurosci. 2:137. doi:10.3389/fnagi.2010.00137

Copyright $\odot 2010$ Eskes, Longman, Brown, McMorris, Langdon, Hogan and Poulin. This is an open-access article subject to an exclusive license agreement between the authors and the Frontiers Research Foundation, which permits unrestricted use, distribution, and reproduction in any medium, provided the original authors and source are credited. 


\section{APPENDIX \\ COGNITIVE ACTIVITY QUESTIONNAIRE}

Please fill in the following tables regarding your hobbies. There are a number of hobbies listed for you. If there any hobbies you participate in that are not listed please fill them in at the end of the table in the space available for "other" activities.

The table first asks you for the number of times a week you complete the activity. In the second column you are asked to fill in the number of months a year you complete the activity. Please fill in all your activities, not just those you are completing in this season. The third column asks you the duration of the activity. This refers to the duration of the activity per session in minutes.

As an example, the first line of the table is filled in for a person who plays board games every Monday night (for $2 \mathrm{~h}$ ) all year round.

\begin{tabular}{llll}
\hline Activity & $\begin{array}{l}\text { Times/ } \\
\text { week }\end{array}$ & $\begin{array}{l}\text { Months/ } \\
\text { year }\end{array}$ & $\begin{array}{l}\text { Duration } \\
\text { (min) }\end{array}$ \\
\hline Example: Board games & 1 & 12 & 60 \\
Board games/chess/checkers & & \\
Play bridge & & \\
Crosswords/word search/Sudoku & & \\
Reading/book club & & \\
Play musical instrument & & \\
Computer/internet & & \\
Draw/paint/ photography & \\
Trivia \\
Arts/crafts/scrapbooking \\
Knitting/sewing/ quilting \\
Puzzles \\
Other: \\
Other:
\end{tabular}

Table A1 | Summary of $\boldsymbol{R}^{2}$ and Beta (standardized) for Cognitive activity (number of activities) in final predictive models of neuropsychological function.

\begin{tabular}{|c|c|c|c|c|c|}
\hline \multirow{2}{*}{$\begin{array}{l}\text { Cognitive } \\
\text { domains }\end{array}$} & \multicolumn{5}{|c|}{ Models ${ }^{a}$} \\
\hline & 1 & 2 & 3 & 4 & 5 \\
\hline \multicolumn{6}{|c|}{ Global score } \\
\hline$R^{2}$ & 0.50 & 0.51 & 0.51 & 0.53 & 0.54 \\
\hline Beta & $0.548 * * *$ & $0.468^{* * *}$ & $0.514^{* * *}$ & $0.461 * *$ & $0.50 * * *$ \\
\hline \multicolumn{6}{|c|}{ Speed of processing } \\
\hline$R^{2}$ & 0.45 & 0.50 & 0.45 & 0.51 & 0.48 \\
\hline Beta & $0.557 * * *$ & $0.436^{* *}$ & $0.473^{* *}$ & $0.407^{* *}$ & $0.521 * * *$ \\
\hline \multicolumn{6}{|l|}{ Attention } \\
\hline$R^{2}$ & 0.32 & 0.38 & 0.32 & 0.34 & 0.36 \\
\hline Beta & $0.318^{*}$ & 0.255 (ns) & $0.334(\mathrm{~ns})$ & 0.280 (ns) & 0.274 (ns) \\
\hline \multicolumn{6}{|c|}{ Executive function } \\
\hline$R^{2}$ & 0.34 & 0.35 & 0.45 & 0.40 & 0.40 \\
\hline Beta & $0.499 * * *$ & $0.448^{* *}$ & $0.506^{* *}$ & $0.418^{*}$ & $0.498^{* *}$ \\
\hline \multicolumn{6}{|c|}{ Verbal memory } \\
\hline$R^{2}$ & 0.29 & 0.30 & ns & ns & 0.27 \\
\hline Beta & $0.361 *$ & 0.268 (ns) & - & - & 0.302 (ns) \\
\hline \multicolumn{6}{|c|}{ Visual memory } \\
\hline$R^{2}$ & 0.22 & ns & 0.29 & 0.33 & ns \\
\hline Beta & $0.448^{* *}$ & - & $0.448^{*}$ & $0.434^{*}$ & - \\
\hline \multicolumn{6}{|c|}{ Verbal ability } \\
\hline$R^{2}$ & 0.28 & 0.56 & 0.46 & 0.42 & 0.33 \\
\hline Beta & $0.409 * *$ & $0.39 *$ & $0.472^{* *}$ & $0.448^{* *}$ & $0.375^{*}$ \\
\hline \multicolumn{6}{|l|}{ Perception } \\
\hline$R^{2}$ & 0.41 & 0.38 & 0.41 & 0.39 & 0.47 \\
\hline Beta & $0.374^{* *}$ & $0.40^{* *}$ & $0.393^{*}$ & 0.297 (ns) & $0.364^{*}$ \\
\hline
\end{tabular}

a Models: 1 = Age, Education, MAP $P_{R E S P}$ Cognitive activity (number), Cognitive activity (hrs); 2 = Age, Education, $M A P_{1 s 0^{\prime}}$ Cognitive activity (number), Cognitive activity (hrs); 3 = Age, Education, $C V C_{R E S P}$ Cognitive activity (number), Cognitive activity (hrs); 4 = Age, Education, $C V C_{I S O}$ Cognitive activity (number), Cognitive activity (hrs); $5=$ Age, Education, $\mathrm{V}_{2}$ max, Cognitive activity (number), Cognitive activity (hrs).

${ }^{*}=p<0.05 ;{ }^{* *}=p<0.01 ;{ }^{* *}=p<0.001 ;$ ns = not significant. 